\title{
DESAIN PENGEMBANGAN KOMPETENSI BIDANG ABSORBSI SISWA KIMIA INDUSTRI SMKN O1 MOJOANYAR - KAB. MOJOKERTO
}

\author{
Anang Takwanto, Prayitno, Zakijah Irfin, Hadi Priya Sudarminto \\ Jurusan Teknik Kimia, Politeknik Negeri Malang
}

\begin{abstract}
Abstrak - Pengabdian masyarakat dilakukan untuk mengenalkan keilmuan bidang Teknik Kimia, di samping juga untuk menerapkan dan menularkan ilmu teknik kimia kepada masyarakat umum Pengabdian masyarakat ini dilaksanakan dengan Dana DIPA, Nomer SP DIPA : 042.01.2.401004/2019 Politeknik Negeri Malang, dengan Nomor Perjanjian : 9731/PL2.1/HK/2019, tempat pengabdian SMKN 01 MOJOANYAR dengan peserta Siswa kelas 2 (dua) Kimia Industri. Judul pengabdian masyarakat adalah Bimbingan Teknis Desain Pengembangan Kompetensi Bidang Absorpsi Untuk Siswa SMKN 01 MOJOANYAR".
\end{abstract}

Kata kunci: absorpsi, Kimia Indusri, Mojoanyar.

\section{PENDAHULUAN}

\subsection{Latar Belakang}

Sesuai Permendikbud Nomor 81A/2013 tentang Implementasi Kurikulum 2013 untuk SD dan yang sederajat, SMP dan yang sederajat, dan SMA dan yang sederajat, maka guru dituntut meningkatkan kompetensi dalam mata pelajaran yang diampunya. Peningkatan kompetensi pada bidang tertentu tersebut menjadi tanggung jawab masing-masing guru. Salah satu metode peningkatan kompetensi adalah dengan cara ikut serta dalam pelatihan tertentu sesuai kompetensi yang diinginkan. Pelatihan kompetensi bagi guru ini tidak mudah dijumpai karena beberapa alasan, antara lain kebutuhan sarana dan prasarana pelatihan yang memadai, serta biaya pelaksanaan pelatihan yang tidak sedikit.

Begitu juga guru-guru kimia di SMK Kimia, yang tergabung dalam wadah Musyawarah Guru Mata Pelajaran (MGMP) Kimia Kota Pasuruan. Pelatihan untuk meningkatkan kompetensinya memliki tuntutan lebih besar. Pelatihan yang diikuti seyogyanya sejalan dengan bidang pengajaran di SMK Kimia Industri. Sebagian besar latar belakang pendidikan guru-guru tersebut adalah di pendidikan kimia, yang belum memiliki pengalaman bersentuhan langsung dengan dunia industri nyata.

Dengan adanya komunikasi antara MGMP Kimia SMA Kota Mojokerto dengan Jurusan Teknik Kimia Politeknik Negeri Malang melalui pertemuan sosialisasi Jurusan Teknik Kimia kepada para guru tersebut, diharapkan permasalahan tersebut dapat teratasi. Hasil komunikasi pada pertemuan tersebut serta dengan melihat sarana laboratorium dan SDM yang dimiliki Jurusan Teknik Kimia, timbul keinginan dari para guru anggota MGMP Kimia SMA Kota Mojokerto untuk meningkatkan kompetensinya dalam bidang kimia industri, khususnya pendalaman dalam proses Absorbsi menggunakan peralatan skala pilot plant. Peralatan Absorbsi skala pilot plant yang dimiliki Jurusan Teknik Kimia memiliki karakteristik yang berbeda dengan skala laboratorium, dan dalam skala yang lebih kecil, sehingga biaya operasional tidak sebesar peralatan skala industri.

Dari uraian diatas, serta berdasarkan surat permohonan pemateri yang diajukan oleh guru-guru yang tergabung dalam MGMP Kimia SMA Kota Mojokerto yang dilayangkan kepada Direktur, maka diusulkan kegiatan pengabdian kepada masyarakat dalam bentuk pelatihan pengembangan kompetensi bidang pengoperasian peralatan absorbsi skala pilot plant .Outcome dari pelatihan tersebut diharapkan timbul peningkatan peran dan kinerja para guru, agar kualitas pembelajaran kimia di masing-masing sekolah meningkat dan lebih mendekati dengan dunia industri yang nyata

Wilayah sekitar Masjid Al Mu'minun RW-12 Kelurahan Lowokwaru Kota Malang adalah pemukiman padat penduduk. Mayoritas masyarakat di wilayah bekerja di sektor swasta, seperti membuat kue atau makanan ringan, membuka toko kecil di rumah untuk berjualan ataupun membuka usaha menjahit/bordir. Banyak di antara keluarga-keluarga tersebut yang memiliki anak pada usia pendidikan dasar (SD sampai SMP), yakni dengan rentang usia antara 7 tahun sampai 15 tahun.

Seperti kita ketahui bersama, pada saat ini, metode pembelajaran yang diterapkan pada level pendidikan dasar telah banyak memanfaatkan komputer dan perangkat lunak pendukung untuk menunjang proses belajar mengajar di sekolah. Di samping itu, mereka harus mempresentasikan hasil kerja mereka secara elektronis dengan menggunakan software presentasi.

Berdasarkan kedua kondisi di atas, maka dapat diambil suatu peluang untuk dapat melaksanakan pengabdian pada masyarakat. Pengabdian pada masyarakat tersebut berbentuk pelatihan Teknik presentasi dan pengoperasian Microsoft Office PowerPoint (MS PowerPoint) pada anak-anak usia pendidikan dasar, dengan harapan mereka dapat mengenal dan memperoleh pengetahuan di dalam mengoperasikan program komputer berkaitan dengan software untuk presentasi. Sehingga akan mempermudah mereka di dalam mengikuti kegiatan belajar di sekolah dan dalam menyelesaikan tugas pekerjaan rumah.

\section{TINJAUAN PUSTAKA}

Absorbsi merupakan salah satu proses pemisahan dengan mengontakkan campuran gas dengan cairan 
sebagai penyerapnya. Penyerap tertentu akan menyerap setiap satu atau lebih komponen gas. Gas yang mengandung zat terlarut, disebut gas kaya (rich gas), masuk ke ruang pendistribusian melalui celah isian, berlawanan arah dengan zat cair. Isian itu memberikan permukaan yang luas untuk kontak antara zat cair dan gas sehingga membantu terjadinya kontak yang maksimal antara kedua fase, dan terjadi penyerapan zat terlarut yang ada di dalam rich gas oleh zat cair yang masuk ke dalam menara dan gas encer (lean gas) keluar dari atas. Sambil mengalir kebawah, zat cair makin kaya zat terlarut, dan keluar dari bawah menara sebagai cairan pekat (strong liquor). Secara skematik proses absorbsi dapat dilihat pada Gambar 2.1.

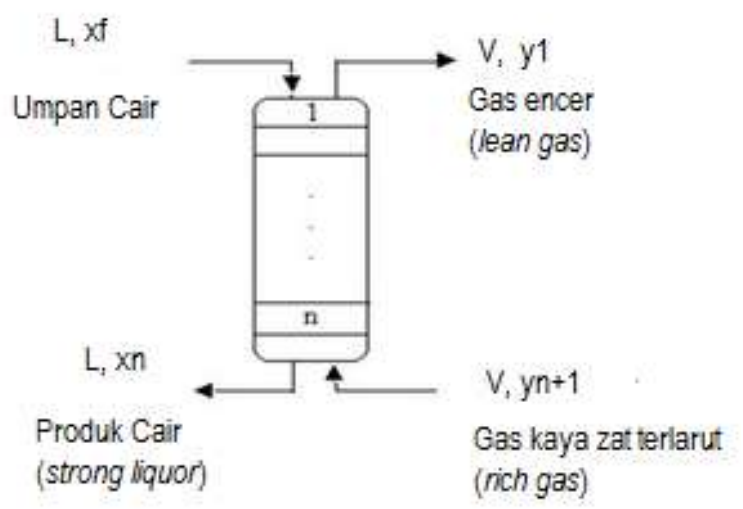

Gambar 1. Skema peristiwa absorbsi

Pada absorbsi sendiri ada dua macam proses yaitu :

\section{a. Absorbsi fisik}

Absorbsi fisik merupakan absorbsi dimana gas terlarut dalam cairan penyerap tidak disertai dengan reaksi kimia. Contoh absorbsi ini adalah absorbsi gas $\mathrm{H}_{2} \mathrm{~S}$ dengan air, metanol, propilen, dan karbonat. Penyerapan terjadi karena adanya interaksi fisik, difusi gas ke dalam air, atau pelarutan gas ke fase cair. Dari asborbsi fisik ini ada beberapa teori untuk menyatakan model mekanismenya, yaitu :

1. teori model film

2. teori penetrasi

3. teori permukaan yang diperbaharui

\section{b. Absorbsi kimia}

Absorbsi kimia merupakan absorbsi dimana gas terlarut didalam larutan penyerap disertai dengan adanya reaksi kimia. Contoh absorbsi ini adalah absorbsi dengan adanya larutan $\mathrm{MEA}, \mathrm{NaOH}, \mathrm{K}_{2} \mathrm{CO}_{3}$, dan sebagainya. Aplikasi dari absorbsi kimia dapat dijumpai pada proses penyerapan gas $\mathrm{CO}_{2}$ pada pabrik amoniak. Penggunaan absorbsi kimia pada fase kering sering digunakan untuk mengeluarkan zat terlarut secara lebih sempurna dari campuran gasnya. Keuntungan absorbsi kimia adalah meningkatnya koefisien perpindahan massa gas, sebagian dari perubahan ini disebabkan makin besarnya luas efektif permukaan. Absorbsi kimia dapat juga berlangsung di daerah yang hampir stagnan disamping penangkapan dinamik.

\section{METODOLOGI PENGABDIAN}

Pelaksanaan PKM dibagi atas tahapan-tahapan ;

1) Persiapan kegiatan pengabdian kepada masyarakat (PKM)

2) Pelaksanaan kegiatan PKM

PKM dilaksanakan di Operasi Teknik Kimia Jurusan Teknik Kimia Polinema. Tahapan pelaksanaan kegiatan di laboratorium adalah sebagai berikut:

a) Tes awal (pre test)

Tes awal dilakukan untuk mengetahui tingkat pemahaman peserta PKM sebelum pelaksanaan PKM.

b) Pembekalan teori tentang Absorbsi, fenomena perpindahan yang terjadi selama peristiwa absoprsi. Pembekalan tentang konsep-konsep Absorbsi diberikan dalam bentuk ceramah klasikal dengan narasumber dosen pembina matakuliah OTK 3 dengan durasi waktu $6 \mathrm{x}$ 45 menit.

c) Pembekalan tentang SOP dan cara kerja alat Absorbsi.

Pembekalan dilakukan di lab.Operasi Teknik Kimia dengan narasumber Pranata Lab. Pendidikan (PLP), durasi waktu 2 x 45 menit.

d) Pembekalan teori tentang persiapan bahan

Bahan-bahan yang digunakan dalam praktikum Absorbsi diperkenalkan ke peserta, cara handling (penanganannya) serta manfaat dan kegunaannya juga dikenalkan. Pembekalan ini dilakukan dengan durasi waktu 2 x 45 menit.

e) Praktek Absorbsi

Praktek Absorbsi dilakukan di lab. Operasi Teknik Kimia Jurusan Teknik Kimia Polinema dengan melakukan demo dilanjutkan dengan praktek yang diikuti oleh semua peserta kegiatan PKM yang hadir. Durasi waktu pelaksanaan adalah 7 x 45 menit agar diperoleh hasil dan pemahaman peserta yang optimal.

f) Praktek analisa produk hasil Absorbsi

Praktek analisa produk hasil Absorbsi dilakukan simultan dengan praktek Absorbsi.

g) Tes akhir (post test) dan pengisian kuesioner.

Tes akhir dilakukan untuk mengetahui tingkat pemahaman peserta PKM setelah pelaksanaan PKM, sedang kuesioner dilakukan untuk mengetahui tingkat kepuasan peserta serta untuk tindakan perbaikan berikutnya.

3) Analisa kegiatan dan penyusunan laporan kegiatan PKM..

\section{HASIL DAN PEMBAHASAN}

Kegiatan pengabdian pada masyarakat bagi guru-guru anggota MGMP Kimia SMA Kota Lamongan dilakukan dengan tujuan untuk:

- Meningkatkan pengetahuan dan pemahaman guruguruanggota MGMP Kimia SMA Kota Lamongan dalam rangka pengoperasian peralatan Absorbsi.

- Melakukan pengenalan sistem operasi terpadu skala pilot plant bagi guru-guruanggota MGMP Kimia SMA Kota Lamongan

Manfaat yang dapat diambil dari kegiatan ini adalah 
- Guru-guruanggota MGMP Kimia SMA Kota Mojokerto mendapatkan pemahaman tambahan dalam rangka pengoperasian peralatan Absorbsi. - Proses pembelajaran di SMK-SMK Kimia Industri Kota Mojokerto berjalan dengan lebih variatif karena guru-guru memperoleh pengalaman nyata dalam pengoperasian perangkat Absorbsi.

- Motivasi belajar peserta didik di SMK-SMK Kimia Industri Kota Mojokerto dapat meningkat karena proses belajar lebih bervariatif.

- Terjalin komunikasi dan kerjasama antara Jurusan Teknik Kimia Polinema dengan guru-guru anggota MGMP Kimia SMA Kota Mojokerto.

- Secara tidak langsung memberikan wawasan tentang Teknik Kimia kepada guru-guru anggota MGMP Kimia SMA Kota Mojokerto, sehingga diharapkan merupakan sosialisasi keberadaan Jurusan Teknik Kimia, khususnya, dan Polinema pada umumnya.

\section{KESIMPULAN}

1. Berdasarkan hasil pengabdian yang telah dilakukan, bahwa materi pelatihan dapat tersampaikan dengan baik dan bisa memberikan pengetahuan tambahan bagi siswa kimia industri SMKN Mojoanyar

2. Dari hasil evaluasi pelatihan didaptkan bahwa para siswa SMK aangat membtuhkan pelatihan keahliah seperti ni, sehingga dengan pelatihan ini dapat menanmbah kempetensi para guru dibidang kimia.

\section{PUSTAKA}

[1]. Coulson, JM., \& Richardson, JF., Chemical Engineering, Vol. 2, Pergamon Press, London, 1980.

[2]. Geankoplis, Christie, Transport Processes and Unit Operation, Allyn \& Bacon, Inc., Boston, 1988.

[3]. Green, Don, Perry's Chemical Engineering Handbook, 6th ed. McGraw-Hill, New York, 1988.

[4]. McCabe, Smith \& Harirot, Unit Operation of Chemical Engineering, 4th ed., McGraw-Hill Book, Co., New York, 1986

[5]. Tim Pengajar OTK 2, Jobsheet Praktikum Operasi Teknik Kimia 2, Jurusan Teknik Kimia, Polinema, 2014. 